\section{SYMPOSIUM N}

\section{Electron Microscopy of Materials}

The symposium on electron microscopy of materials was the sequel to two specialized MRS symposia concerning high resolution microscopy (1980) and electron microscopy and chemical analysis (1981). Three full days were devoted to a broad discussion of developments in instrumentation, image interpretation and applications to metals, semiconductors, and ceramics. Some outstanding invited talks and excellent contributed papers from a truly international representation of the microscopy and materials communities assured the attainment of the organizers' intention of providing a forum for microscopists and materials scientists to interact in a unique way.

Some highlights were:

Gronsky (Berkeley) reporting on the atomic resolution microscope revealing the structure of $\mathrm{Al}-\mathrm{Ag}_{2} \mathrm{Al}$ interface; Williams (Lehigh) controversially pointing out advantages of X-ray energy dispersive spectrometry over electron energy loss for analysis even of the low atomic number elements; Krakow (IBM) giving an impressive demonstration of the power of image processing for analysis and interpretation of electron micrographs including dynamic observations of surface diffusion on $\mathrm{Ag}_{2} \mathrm{O}$.

Petroff (Bell Labs) showing how surface sensitive microscopic techniques could be applied to show new features of surface reconstruction on semiconductors. This theme was ably taken up and further developed by Cowley (ASU) with illustrations from the fields of crystal growth and surface reactions. The power and utility of the cross sectioning technique were illustrated by the work of Kuan (IBM), while Tu (IBM) reported some extraordinary phase transformations in metal-silicon reactions. Grain boundary structure in a wide variety of materials was discussed by Ast (Cornell), Carter (Cornell), Clark (OSU), and Ruhle (Stuttgart).

The contributed papers focused on non-metals and included such studies as the hydration of Portland cement

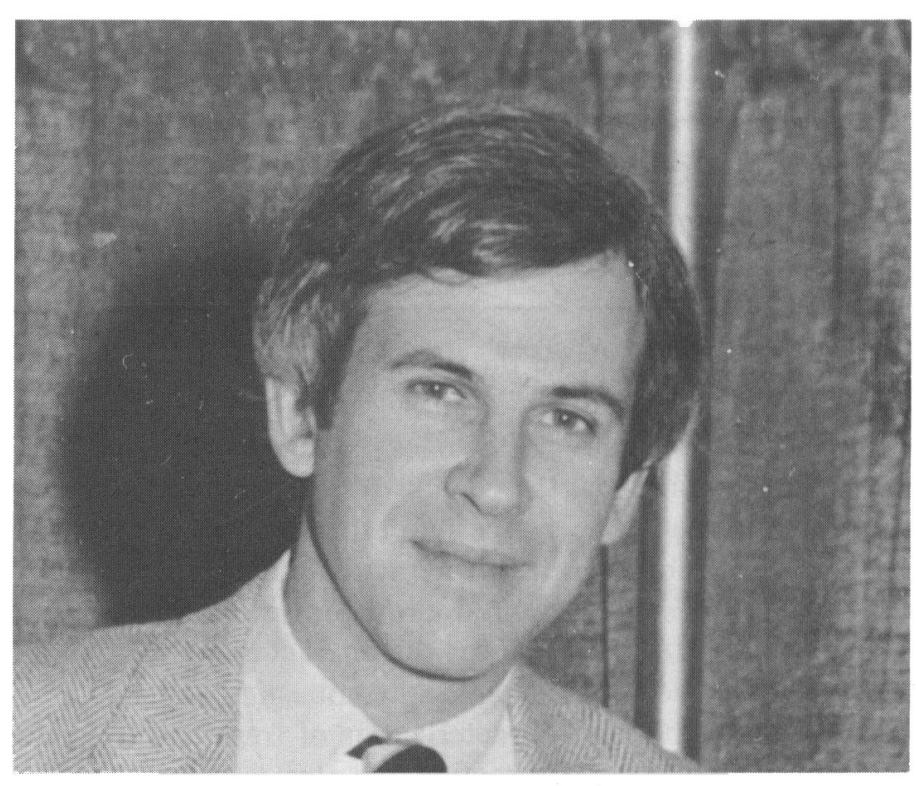

\section{LINN HOBBS}

(Pratt, Imperial College), phase transformations in $\mathrm{Al}_{2} \mathrm{O}_{3}$ (Tucker, University of Florida), crystallinity of B-doped polysilicon (Rajeswara, Brookhaven), and heteroepitaxy in $\mathrm{ZnSe}$ growth on GaAs and Ge (Ponce, Hewlett-Packard). Two of the younger scientists-Sands (Berkeley) and Morrissey (Cornell)-were honored with MRS Student Awards.

\section{W. Krakow}

D.A. Smith

International Business Machines Corporation

L.W. Hobbs

Massachusetts Institute of Technology

Chairmen

\section{Symposium Support \\ JEOL USA Inc. IBM}

Hitachi Scientific Instruments

Philips Electronic Instruments, Inc.

\section{SYMPOSIUM X}

\section{Frontiers Of Materials Research}

With two consecutive successful years at the MRS Annual Meeting, Symposium $\mathrm{X}$ has approached the proven concept stage. Again this year the review talks spanned many symposia and enjoyed attendance of between 100 and 200 each day. Topics included ion implantation, the materials science of rad-waste management, chemical bonding in metals, electronic ceramics, grain structure in metals, electron microscopy, and reliability in brittle solids.
The list of distinguished speakers included C.W. White, Oak Ridge, A.E. Hughes of Harwell, Roger Doherty of Drexel, Leo Brewer and A.R. Evans of U.C.-Berkeley, P.B. Hirsch of Oxford and Rustum Roy and R.E. Newnham of Penn State.

The symposium was again co-sponsored with the Educational Modules for Materials Science and Engineering Project, which will publish the proceedings in the form of modules in a special issue of the Journal of Materials Education in 1984.

\section{Rustum Roy}

Pennsylvania State University

Chairman 